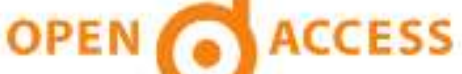

\section{International Journal of Applied Sciences and Biotechnology}

\author{
A Rapid Publishing Journal
}

ISSN 2091-2609

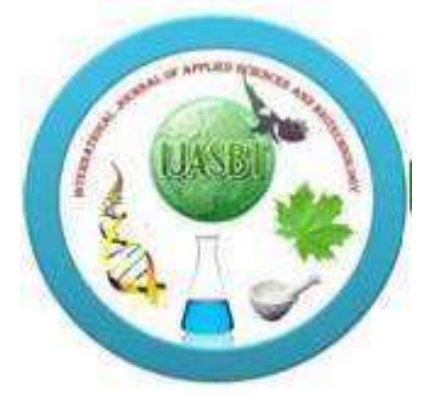

Available online at:

http://www.ijasbt.org

\&

http://www.nepjol.info/index.php/IJASBT/index

\section{Indexing and Abstracting}

CrossRef, Google Scholar, Global Impact Factor, Genamics, Index Copernicus, Directory of Open Access Journals, WorldCat, Electronic Journals Library (EZB), Universitätsbibliothek Leipzig, Hamburg University, UTS (University of Technology, Sydney): Library, International Society of Universal Research in Sciences (EyeSource), Journal Seeker, WZB, Socolar, BioRes, Indian Science, Jadoun Science, Jour-Informatics, Journal Directory, JournalTOCs, Academic Journals Database, Journal Quality Evaluation Report, PDOAJ, Science Central, Journal Impact Factor, NewJour, Open Science Directory, Directory of Research Journals Indexing, Open Access Library, International Impact Factor Services, SciSeek, Cabell's Directories, Scientific Indexing Services, CiteFactor, UniSA Library, InfoBase Index, Infomine, Getinfo, Open Academic Journals Index, HINARI, etc.

\section{CODEN (Chemical Abstract Services, USA): IJASKD}

Vol-2(4) December, 2014

Impact factor*: $\mathbf{1 . 4 2 2}$

Scientific Journal Impact factor ${ }^{\#}: 3.419$

SEM-Biotech

Index Copernicus Value: $\mathbf{6 . 0 2}$

Publishing

*Impact factor is issued by Universal Impact Factor. Kindly note that this is not the IF of Journal Citation Report (JCR).

"Impact factor is issued by SJIF INNO SPACE. 


\title{
BIOPHYSICAL AND CHARACTERIZATIONS OF SILVER NANOPARTICLES USED AS SALMONELLA TYPHI DETECTOR
}

Hala Moustafa Ahmed

Medical Biophysics Department, Faculty of Applied Medical Science, October 6 University, Egypt.

Corresponding author's email: Bakar_tarek_76@hotmail.com

\begin{abstract}
The present study mainly focuses of combined action of Nepali hog plum as well as citrate synthesized silver nanoparticles (AgNPs) and Amikacin, as an antibiotic. The synergistic actions of citrate stabilized silver nanoparticles (AgNPs with chem) were compared with that of Nepali hog plum Choerospondia saxillaris (Lapsi) synthesized silver nanoparticles (AgNPs with plant), together with action of antibiotic on selected bacterial strains of Salmonella typhi.The synthesized AgNPs were characterized through UV-Vis spectroscopy, Transmission electron microscopy and X-ray diffraction technique. The size of the synthesized silver nanoparticles was measured by Transmission Electron Microscope (TEM) and X-ray diffraction (XRD).
\end{abstract}

Keywords: AgNPs; Salmonella typhi; microorganism; TEM; antibiotics.

\section{Introduction}

Concern regarding engineered nonmaterial safety is currently receiving considerable attention in the scientific, academic, industrial, and regulatory communities because of uncertainties regarding the environmental impact of such materials (Meng et al., 2009).Silver nanoparticles (AgNPs), as a water pollutant; have been reported to affect numerous environmental systems, such as bacteria cells (Pal et al., 2007), aquatic organisms such as zebra fish, and algae (Navarro et al., 2008). Recently, it has been published that the antibacterial mechanism of AgNPs is related to the formation of free radicals and subsequent free radicalinduced membrane damage (Danilczuk et al., 2006; Kim et al., 2007). Hwang et al. (2008) reported a synergistic toxic effect of the AgNPs and silver ions. The ions move into the cells and produce reactive oxygen species (ROS). In addition, membrane damage caused by the AgNPs caused an increase in cell permeability leading to an uncontrolled transport through the cytoplasmic membrane and ultimately cell death (Sondi et al., 2004; Morens et al., 2005).

Many antimicrobial agents are limited in clinical applications, because of their poor membrane penetration, complications and side-effects especially at higher doses and relatively higher incidence of bacterial infection. These limitations due to growing resistance of bacteria to conventional antibiotics and due to in judicial use of many antibiotics (Rai et al., 2009). So the use of nanomaterials are being increasingly applied for medical uses and great interest as an approach to killing or limiting the activity of numerous micro-organisms (Lara et al., 2011). AgNPs exposure, show significant changes in the membranes, which are recognized by the formation of "pits" on their surfaces, and finally, result in the formation of pores and cell death in microbes and is recognized as the best nanoparticles for antibacterial activity (Sondi et al., 2004).

The process of preparation of AgNPs by the reduction of $\mathrm{Ag}^{+}$ions by combinations with bio-molecules found in plant extracts has gain a lot of interest. The capabilities of some microorganisms such as bacteria and fungi to direct the synthesis of metallic nanoparticles have been increasingly employed in the hunt for new materials. Currently, the investigation of this fact has regained importance due to increase in bacterial resistance to antibiotics, caused by their overuse (Prabhu and Poulose, 2012).

In the current study, chemical as well as plant mediated or biogenic synthesis processes were used for the synthesis of silver nanoparticles. Synergistic potential of these silver nanoparticles helps in the enhancement of antibacterial activity of the antibiotic. The synergistic action of amikacin with silver nanoparticles can reduce the need for high dosages of antibiotics and minimize their side effects (Essex et al., 1997).

The dielectric behavior of biological tissue depends upon the properties of the molecules comprising, their size, shape and the polarizability and other factors like surface charges, bound water, hydration water and other factors (Essex et al., 1997). Enhancement of antibacterial activities of antibiotics in combination with AgNPs against different strains of 
bacteria have already been reported by many researchers

(Dhas et al., 2013).

The aim of the present work is to study the synergistic effect which demonstrates that antibiotic, biogenically synthesized silver nanoparticles (AgNPs with plant) and chemically synthesized silver nanoparticles (AgNPs with chem) using sodium citrate exhibit improved bactericidal activities, and more interestingly, a synergistic activity becomes operational when both of the components act together. The antibacterial activities against Salmonella typhi were studied by using gel-diffusion method.

\section{Materials and Methods}

\section{Sample Preparation}

For biogenic synthesis of silver nanoparticles (Ag-NPs), Nepali hog plum (Choreospondias axillaris) extract was used as the biological source. The extract of Choreospondias axillaris was used for reduction and capping, which was purchased from local market. In chemical synthesis sodium citrate was used as capping and reducing agent. Silver nitrate $\left(\mathrm{AgNO}_{3}\right)$ was used as precursor in the both methods, which was purchased from Sigma Aldrich Chemicals (USA).

\section{Synthesis of Silver Nanoparticles AgNPs}

Biogenic synthesis of AgNPs was done by using fruit of Choreospondias axillaris extract (Essex et al., 1997). Fruits were thoroughly washed in deionized water, outer seed covering of the fruit was peeled off and the fleshy part was taken out, $10 \mathrm{gm}$ of this flashy part was added in $100 \mathrm{ml}$ of deionized water, boiled for 30 minutes, and filtered through Whattmann no. 1 filter paper. Equal volume of pale white lapsi extracts was added to an equal quantity of $0.1 \mathrm{M}$ aqueous silver nitrate $\left(\mathrm{AgNO}_{3}\right)$ solution by volume and then was kept in the incubator shaker under $37^{\circ} \mathrm{C}$ for 24 hours. During this period, the color change was observed from whitish color to the faint yellow color due to the bioreduction of $\mathrm{Ag}^{+}$ions $\left(\mathrm{Ag}^{+}\right.$to $\left.\mathrm{Ag}^{0}\right)$. The reactants were then characterized at intervals to detect the presence of silver nanoparticles. The percentage of silver nanoparticles in the reaction medium was enhanced by three cycles of centrifugation at 10,000 r.p.m for 3 minutes followed by redispersion in deionized water.

Chemical synthesis of AgNPs was done by using Lee and Meisel's method (Lee and Meisel, 1982). Aqueous solution of $125 \mathrm{ml}$ silver nitrate $(1.0 \mathrm{mM})$ was heated till it boils and added $5 \mathrm{ml} 1 \%$ citrate of sodium $(1.0 \mathrm{mM})$ in the mixture as a reducing agent. Citrate of sodium can be also used as stabilizing agent at room temperature. The transparent colorless solution was converted to the characteristic pale yellow, which indicates the formation of AgNPs. It was then cooled to room temperature with constant stirring and stored in brown bottle at very low temperature used for further characterization and applications.

\section{Characterizations of the prepared AgNPs}

UV-Visible spectral analysis was performed on SSI UV2101Spectrophotometer machine at SANN International College, Kathmandu to observe Surface Plasmon Resonance (SPR) which exhibited by AgNPs. Diluted solution of AgNPs was taken as a sample in cuvette. Spectrum was obtained by scanning the sample from 200$600 \mathrm{~nm}$.

X-ray powder diffraction technique was used for phase identification of AgNP crystal and obtained information on unit cell dimensions. It is the simplest and most widely used method for estimating the average crystallite size from the full width at half maximum (FWHM) of a diffraction peak using the Scherrer equation (Varshney et al., 2010). The XRD analysis was performed on D2 Phase machine ((Philips Duo-diagnost code RDXR001)) at VACSERA. For this purpose sample of AgNPs with chem and AgNPs with plant were prepared by centrifugation for about 30 minutes at $5000 \mathrm{rpm}$. The pellet thus obtained was cast on a glass slide and left overnight for drying. It was then it examined in XRD machine for analysis. Using a fluoroscopic $\mathrm{x}$-ray machine $46 \mathrm{Kv}$ and $5 \mathrm{mAs}$, was used to image the synthesized.

\section{Transmission Electron microscope scanning}

TEM analysis was performed to determine the particle size and distribution of nanoparticles. Colloidal AgNPs solution was used as a sample for TEM analysis. TEM analysis was performed on JEOL at VCSERA. The adjutants were diluted with water until the solid content was $0.01 \%$. The copper grid was dipped into the suspension and allowed to air dry. Pictures were taken in a JEOL-JEM-1230 transmission electron microscope at a $\mathrm{x}$ 40,000 magnification (Nazareth et al., 2014).For obtaining transmission electron microscopy (TEM) images, bacteria samples were fixated in a composition of $2 \%$ para formaldehyde and $2 \%$ glutaraldehyde in $0.12 \mathrm{M}$ Sorensen's buffer at $\mathrm{pH} 7.4$, then post fixated and stained in $2 \%$ osmium tetra oxide solution for $1 \mathrm{~h}$ at $4^{\circ} \mathrm{C}$. To eliminate any possibility of artifacts, the post staining steps with uranyl acetate and lead citrate were omitted. After dehydration, embedding sections were cut on aMT6000 ultra microtome (Sorvall, New Castle, DE). Thin sections $(0.1 / 0.05 \mathrm{~mm})$ were examined and photographed using a JEOL 100CX electron microscope (JEOL-USA, Peabody, MA).

\section{Synergistic Interaction between Silver Nanoparticles and Antibiotic}

Well diffusion method was used to assay the synergistic effect of Amikacinwith plant mediated synthesized and citrate synthesized silver nanoparticles for bactericidal activity against test strain on Muller Hinton agar plates. Briefly, a $5 \mathrm{~mm}$ well made by cork-borer was impregnated with different test samples on Salmonella typhi cultured agar plates. The Cultured agar plates were then incubated 
for 24 hours at $37^{\circ} \mathrm{C}$. A zone of inhibition was observed for different test samples and their diameter was measured (Fayaz et al., 2010).

\section{Results and Discussion}

\section{Synthesis and Characterizations}

In the present study, silver nanoparticles were synthesized using lapsi (Choreospondias axillaris) and sodium citrate, respectively. When the reducing agents were mixed with aqueous solution of the silver nitrate, they started to convert the color from colorless to yellowish brown due to reduction of silver ion, which indicated the formation of silver nanoparticles (Mukunthan et al., 2011; Hari et al., 2013). The reduction of silver ionwas mainly due to the presence of photo chemicals such as flavonoids, phenols, and ascorbic acid, present in Choreospondias axillaris extract. The synthesis of silver nanoparticles by reduction of pure $\mathrm{Ag}^{+}$ions was monitored by measuring the UV-Vis spectrum. The UV-visible analysis Fig(1) showed that the absorption peaks at 525 and $567 \mathrm{~nm}$ for AgNPs with chem and AgNPs with plant were mainly due to the Surface Plasmon Resonance (SPR) of silver nanoparticle, and the broadening of the peak indicated that the particles are poly dispersed (Fig.1). The detected peaks at 525 and $567 \mathrm{~nm}$ are in good agreement with the theoretical simulation of SPR using Mie's theory (Baset et al., 2011) and different experimental results.

Fig. 2 illustrated the recorded XRD patterns of AgNPs synthesized by both the routes. A number of strong brag reflections can be seen which correspond to (111), (220), (200) at $2 \theta$ reflections of fcc silver in both the AgNPs samples (Varshney et al., 2010). The XRD results exhibited the silver nanoparticles formed are crystalline. Additionally, the diffractions at around $2 \theta=28^{\circ}$ and $38^{\circ}$ resulting from the biomass or the biomass residue are also notable in the AgNPs with plant sample. The size of the AgNPs was estimated from the Debye -Scherrer formula for both the samples were found to be $28 \mathrm{~nm}$ and $46 \mathrm{~nm}$ by using plant mediated and chemical route respective.

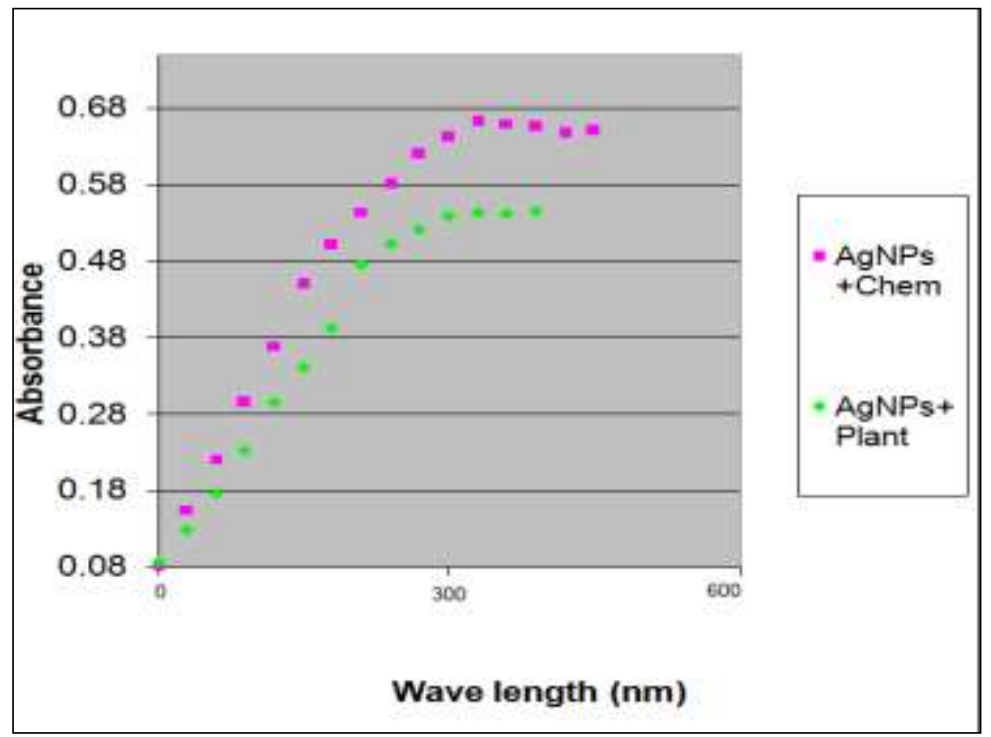

Fig. 1: UV.Vis spectal analysis of AgNPs with chem. and AgNPs with plant at 1:2 AgNPs/water ratio.

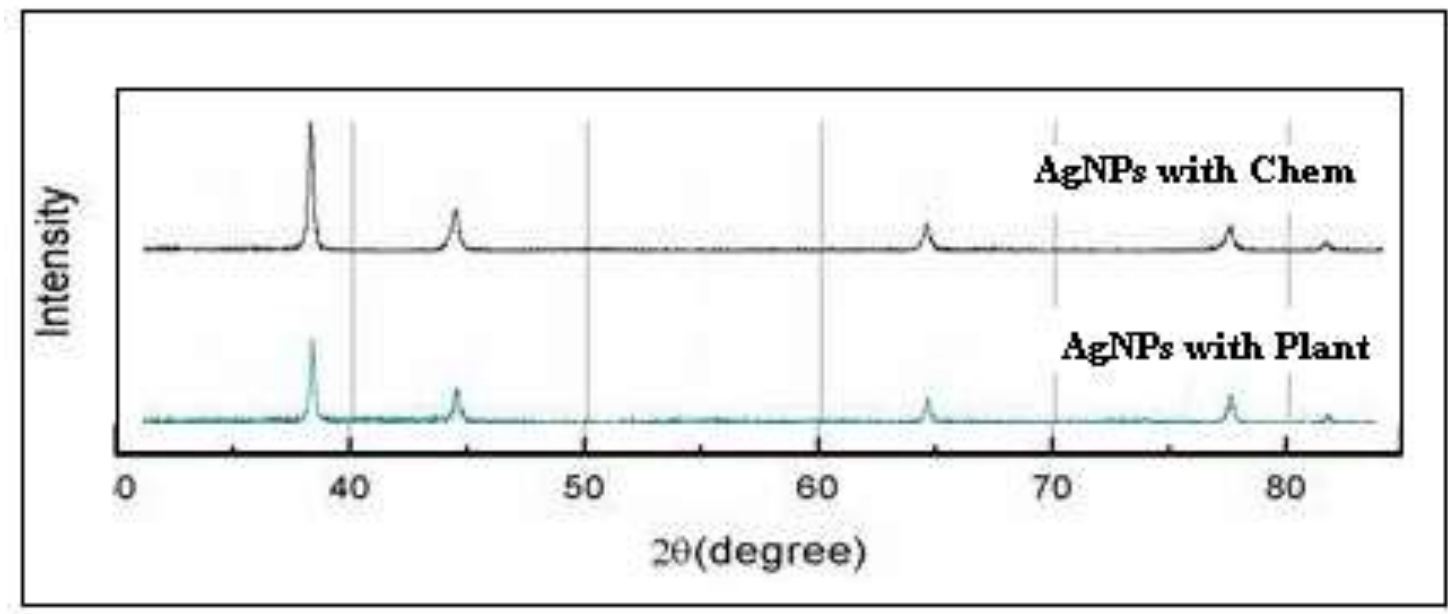

Fig. 2: XRD image of AgNPs with chem and AgNPs with plant at $2 \theta$ degree. 
The size and shape of AgNPs was deduced through transmission electron micrographs at various magnifications ranging (50000-15000X) or (15000X 50000). At 15000X, the majority of AgNPs with it has shown size $50 \mathrm{~nm}$ (Fig. 3a \& 3b). Subsequent increase in magnification has indicated the prominent presence of $\mathrm{Ag}$ with chem with size $50 \mathrm{~nm}$ and irregular shape with some agglomerations. In the same way TEM analysis was performed for $\mathrm{Ag}$ with plant at the same magnifications range (50000-15000X). The nanoparticles were evenly dispersed with different shape (Fig. 3c \& 3d). Detailed analysis showed that $\mathrm{Ag}$ with plant appeared as clusters comprising size of $30 \mathrm{~nm}$ (Li et al., 2010).

\section{Antibacterial Assay}

The AgNPs synthesized by both routes were investigated against Gram-negative Salmonella typhi bacteria in combination with Amikacin, antibiotic using the well diffusion method. Both AgNPs with chem as well as AgNPs with plant showed a very slight difference in their antibacterial activities. This implies that an average particle size range from 30 to $50 \mathrm{~nm}$ imposes almost similar effect over bacteria or the size differences at this range have a very minimal difference in anti-bacterial activities.

The diameters of zone of inhibition $(\mathrm{mm})$ of antibiotic with and without AgNPs against test strains were measured; Amikacin antibiotic, showed an enhanced antibacterial activity in combination with AgNPs and the percentage fold increase in zone of inhibition over Amikacin was recorded; it was found that AgNPs with chem. The antibiotic showed $9.66 \%$ fold increase against Salmonella typhi (Fig. 4). However, AgNPs with plant (30 g/ml) showed $20.16 \%$ fold increase against Salmonella typhi (Fig. 5).

Fig. 4 and Table 1 showed the inhibitory effect of different chemicals on the tested strain of bacteria Salmonella typhi. The study against Salmonella typhi indicates that the silver nitrate (a) imposed very low antibacterial effect while a very small inhibition zone was formed, in addition, its effect was significantly increase with AgNPsplusechem The AgNPs with chem in combination with Amikacin (d) exhibited slight higher inhibitory activity than amikacin (c) alone . However, sodium citrate showed no antibacterial effect.

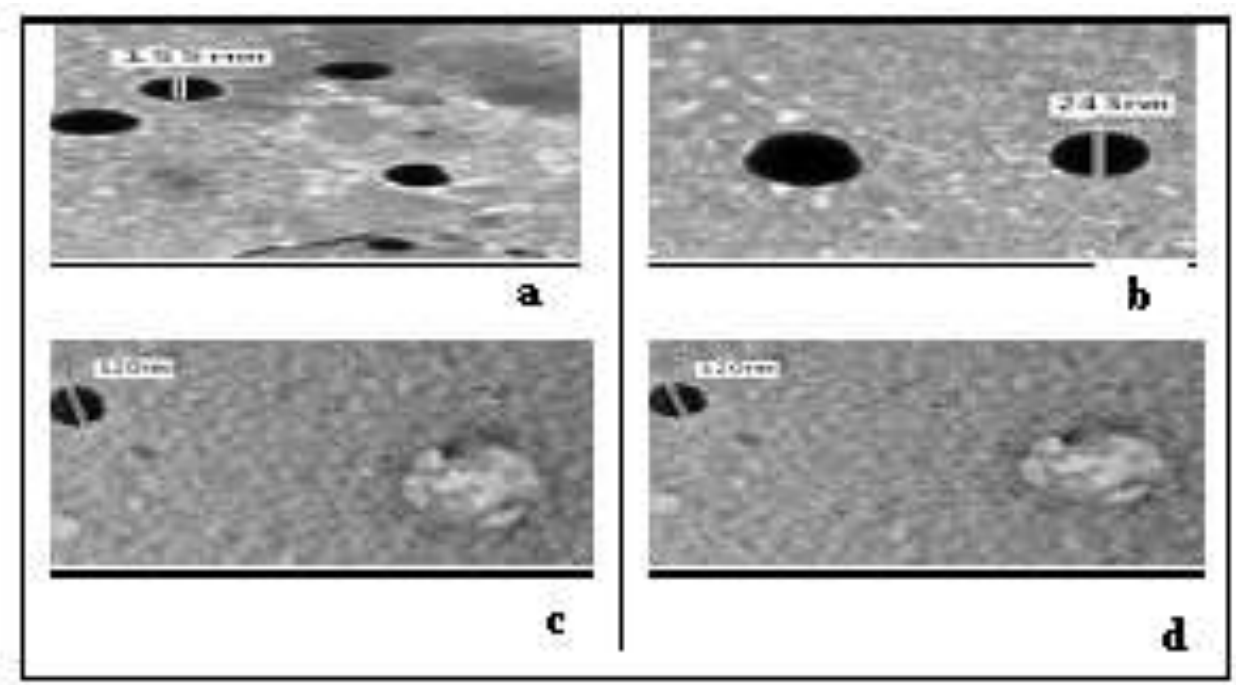

Fig. 3: TEM images of AgNPs with chem (a \& b) and AgNPs with plant (c \& d) at 15000X - 50000X magnification.

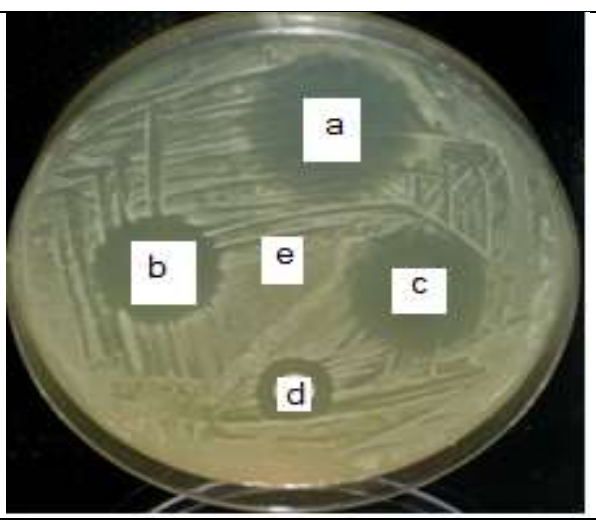

Fig. 4: Activity of Amikacin with AgNPs with chem against Salmonella typhi a: $\mathrm{AgNO}_{3}$, b: AgNPs with chem, c: Amikacin, d: AgNPS with Chem+ Amikacin and e: Sodium citrate.

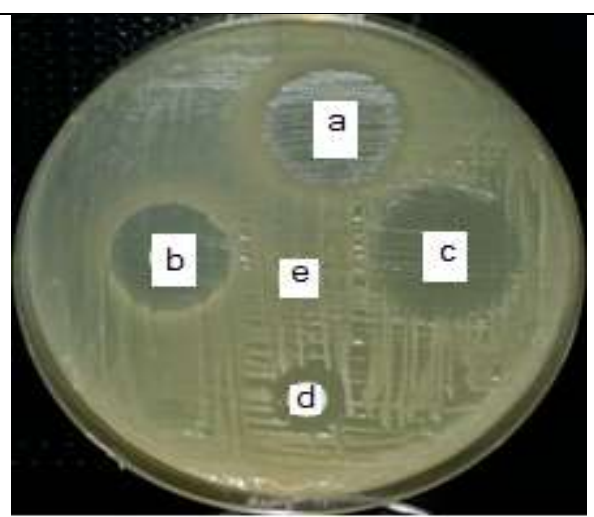

Fig. 5: Synergistic activity of Amikacin with AgNPs with plant against Salmonella typhia: $\mathrm{AgNO}_{3}$, b: AgNPs with plant, c: Amikacin, d: AgNPS with plant+ Amikacin and e: plant extract. 
Table 1: Synergetic activity of Amikacin with AgNPs pluse chem against Salmonella Typhi

\begin{tabular}{|l|l|l|l|l|l|l|}
\hline Microorganism & AgNO3 & $\begin{array}{l}\text { AgNPs with } \\
\text { Chem }\end{array}$ & Amikacin & $\begin{array}{l}\text { AgNPs with Chem + } \\
\text { Amikacin }\end{array}$ & $\begin{array}{l}\text { Sodium } \\
\text { citrate }\end{array}$ & $\begin{array}{l}\text { \%Fold } \\
\text { increase* }\end{array}$ \\
\hline S. typhy & $0.66 \pm 0.27$ & $3.3 \pm 0.09$ & $3.3 \pm 0.19$ & $3.6 \pm 0.23$ & Nil & 9.66 \\
\hline
\end{tabular}

Table 2: Synergetic activity of Amikacin with AgNPs pluse plant against Salmonella typhi

\begin{tabular}{|l|l|l|l|l|l|l|}
\hline Microorganism & AgNO3 & $\begin{array}{l}\text { AgNPs with } \\
\text { Plant }\end{array}$ & Amikacin & $\begin{array}{l}\text { AgNPs with } \\
\text { Plant }+ \\
\text { Amikacin }\end{array}$ & $\begin{array}{l}\text { Sodium } \\
\text { citrate }\end{array}$ & $\begin{array}{l}\text { \%Fold } \\
\text { increase* }\end{array}$ \\
\hline S. typhy & $1.6 \pm 0.59$ & $3.5 \pm 0.30$ & $3.5 \pm 0.20$ & $3.9 \pm 0.44$ & Nil & 20.16 \\
\hline
\end{tabular}

*Over Amikacin

From Fig 5 and Table 2 in the case of AgNPs with plant, Amikacin showed the most pronounced antibiotic synergy against Salmonalla typhi (20.16\% fold increase). Study against Salmonalla typhi showed that the silver nitrate (a) imposed very low antibacterial effect and an exhibited a inhibition zone of $1.6+0.59 \mathrm{~mm}$ while the effect of AgNPs with plant (b) was nearly double $3.5+0.30 \mathrm{~mm}$. Moreover, the effect of AgNPs with plant (b) and Amikacin (c) alone was found to be almost similar.

The Similar pattern of activity was observed in different chemicals test against $S$. typhi. Where the inhibitory activity of AgNPs plus plant and earlier the zone of inhibition found over AgNO3 and increased from $1.6 \pm 0.59 \mathrm{~mm}$ to $3.5 \pm 0.30$ $\mathrm{mm}$. while, the enhancement of the inhibitory activity of amikacin was found in the presence of AgNPs with plant with increase $16.2 \%$ fold as the zone of inhibition increases from $3.5 \pm 0.20 \mathrm{~mm}$ to $3.9 \pm 0.44 \mathrm{~mm}$ when Amikine was tested alone. Plant extract was not found to show Amikacin effect against $S$. typhy.

The antibacterial activity of Amikacin, increased in the presence of AgNPs against Salmonella typhi, and the synergistic effect of the AgNPs was found to more prominent than the effect of antibiotics alone. High surface to volume ratio of AgNPs allows them to interact with antibiotics. Moreover, the presence of active groups such as hydroxyl and amido groups in antibiotics may also enable them to interact with nanosilver by chelation, which may result of the enhancement synergistic effect. More recently,Batarseh's research (Batarseh, 2004) showed that the bactericidal effect was caused by silver (I) chelating, which prevents DNA from unwinding (Batarseh, 2004). The synergistic antibacterial effect with the combination of nano silver and amikacin demonstrated more potential, when compared with other antibiotics.AgNPs synthesized by green route also showed an increased antimicrobial activity against Staphylococcusaureus, Escherichia coli, Salmonella typhi andCandidaalbicans in combination with amikacin.(Dhas et al., 2013; Dar et al., 2013).

Recently, Bhande et al., 2013) have demonstrated that antibiotics showed enhanced synergism with $\mathrm{ZnO}$ nanoparticles against extended spectrum-lactamases producers implicated in urinary tract infections. In their work, they proposed that the combination of $\mathrm{ZnO}$ nanoparticle and antibiotic increased the permeability of membrane which resulted in the leakage of protein from the membrane of bacteria. The results obtained in the current study on combined effects of antibiotics with AgNPs are in agreement to those of earlier studies reported.

\section{Conclusions}

In this study, a new approach of synthesis of AgNPs with plant by using Nepali hog plum Choerospondias axillaries extract was developed with conventional chemical method of synthesis. The synthesized nanoparticles were characterized by different analytical techniques viz. UVVisible spectroscopy to ensure the Surface Plasmon Resonance characteristic colloid AgNPs; XRD analysis for particle size, crystal structure determination; and similarly TEM analysis was carried out to study the particle size and its distribution. The synthesized AgNPs can be applied for a wide range of practical uses, and demonstrates excellent antibacterial performance against Gram-negative Salmonella typhi, with much greater efficacy than ionic $\mathrm{Ag}$ or commercial crystalline Ag micro particles. Synergistic study showed that the antibacterial effect of amikacin was found to be increased in combination with AgNPs synthesized by both the methods. The AgNPs with plant was found to be smaller in size and showed more inhibitory activity than AgNPs with chem in the individual study as well as in synergistic study with amikacin against both the tested bacterial strain. Thus, the developed green synthesis approach by using extract of Choerospondias axillaries provides an effective non-toxic mode of synthesis of AgNPs that can be used as an antibacterial agent. Finally, in the present work AgNPs synthesized by both the methods exhibited potent antibacterial effects on tested bacteria, probably through destruction of membrane integrity. Therefore from the obtained results it can be concluded that AgNPs has considerable antibacterial activity, deserving further investigation for clinical applications. These changes in the membrane mechanical properties because changes in the membrane permeability which can be a reason for the noticed destruction of the microbial cellular membrane 
noticed in the TEM images for the treated microbe by Salmonella typhi.

\section{References}

Baset S, Akbari H, Zeynali H and Shafie M (2011) Size measurement of metal and semiconductor nanoparticles via UV-Vis absorption spectra. Digest Journal of Nanomaterials and Biostructures 6(2): 709-716.

Batarseh KI (2004) Anomaly and correlation of killing in the therapeutic properties of silver (I) chelation with glutamic and tartaric acids. J. Antimicrobiaial. Chemotherapy 54: 546-548. DOI: 10.1093/jac/dkh349

Bhande RM, Khobragade CN, Mane RS and Bhande S (2013) Enhanced synergism of antibiotics with zinc oxide nanoparticles against extended spectrum b-lactamase producers implicated in urinary tract infections. $J$. Nanoparticle Res. 15: 1413. DOI: 10.1007/s11051-012$1413-4$

Danilczuk M, Lund A, Sadlo J, Yamada H and Michalik J (2006) Conduction electron spin resonance of small silver particles. Spectrochim Acta A Mol. Biomol. Spectrosc. 63: 189-191. DOI: 10.1016/j.saa.2005.05.002

Dar MA, Ingle A and Rai M (2013) Enhanced antimicrobial activity of silver nanoparticles synthesized by Cryphonectria sp. evaluated singly and in combination with antibiotics. Nanomed. 9: 105-110. DOI: 10.1016/j.nano.2012.04.007

Dhas SP, Mukherjee A and Chandrasekaran N (2013) Synergistic effect of biogenic silver nanocolloid in combination with antibiotics: a potent therapeutic agent. Intl. J. Pharma. Pharmaceut. Sci. 5: 292-295.

Essex GC, Grant EH, Shepphard RJ, South GP, Symonds MS, Mills GL and Slack J (1997) Dielectric properties of normal and abnormal -lipoproteins in aqueous solution. Ann. N.Y. Acad. Sci. 303:142. DOI: 10.1111/j.1749-6632.1977.tb55927.x

Fayaz AM, Balaji K, Girilal M, Yadav R, Kalaichelvan PT, and Venketesan R (2010) Biogenic Synthesis of Silver Nanoparticles and Their Synergestic Effect with Antibiotics: A Study against Gram Positive and Gram Negative Bacteria. Nanomedicine, 6: 103-109. DOI: 10.1016/j.nano.2009.04.006

Grandolfo M, Michaelson SM and Rindi A (1983) Biological Effects and Dosimetry of Nonionizing Radiation. Plenum Press, New York.

Hari N, Thomas TK and Nair AJ (2013) Comparative Study on the Synergistic Action of Garlic Synthesized and Citrate Capped Silver Nanoparticles with $\beta$-Penem Antibiotics. ISRN Nanotechnol. 792105. DOI: 10.1155/2013/792105

Hwang ET, Lee JH, Chae YJ, Kim YS, Kim BC, Sang BI and Gu MB (2008) Analysis of the toxic mode of action of silver nanoparticles using stress-specific bioluminescent bacteria. Small 4: 746-750. DOI: 10.1002/smll.200700954

Kim JS, Kuk E, Yu KN, Kim JH, Park SJ and Lee HJ (2007) Antimicrobial effects of silver nanoparticles. Nanomed. $\mathbf{3}$
95-101. DOI: 10.1016/j.nano.2006.12.001 Lara HH, GarzaTrevino EN, Turrent LI and Singh DK (2011) Silver nanoparticles are broad-spectrum bactericidal and virucidal compounds. J. Nanobiotechnol. 9: 30. DOI: 10.1186/14773155-9-30

Lee PC and Meisel D (1982) Adsorption and surface-enhanced Raman of dyes on silver and gold sols. J. Phy. Chem., 86: 3391-3395. DOI: 10.1021/j100214a025

Li WR, Xie XB, Shi QS, Zeng HY, Yang YSOU and Chen YB (2010) Antibacterial activity and mechanism of silver nanoparticleson Escherichia coli. Appl. Microbiol. Biotechnol. 85: 1115-1122. DOI: 10.1007/s00253-0092159-5

Meng H, Xia T, George S and Nel AE (2009) A Predictive Toxicological Paradigm for the Safety Assessment of Nanomaterials. ACS NANO 3: 1620-1625. DOI: $10.1021 / \mathrm{nn} 9005973$

Morones JR, Elechiguerra JL, Camacho A, Holt K, Kouri JB, Ramirez JT and Yacaman MJ (2005) The bactericidal effect of silver nanoparticles. Nanotechnology 16: 2346-2353. DOI: $10.1088 / 0957-4484 / 16 / 10 / 059$

Mukunthan KS, Elumalai EK, Patel TN and Murty VR (2011) Catharanthus roseus: a natural source for the synthesis of silver nanoparticles. Asian Pacific J. Tropic. Biomed. 1(4): 270-274. DOI: 10.1016/S2221-1691(11)60041-5

Navarro E, Piccapietra F, Wagner B, Marconi F, Kaegi R, Sigg L and Behra R (2008) Toxicity of Silver Nanoparticles to Chlamydomonas reinhardtii. Environ. Sci. Technol. 42: 8959-8964. DOI: 10.1021/es801785m

Nazareth C, Keny SM and Sawaikar L (2014) Developmental Studies on Alginate Films for Ophthalmic Use. Scholars Academic J. Pharm. 3(1): 1-5.

Pal S, Tak YK and Myong SJ (2007) Does the Antibacterial Activity of Silver Nanoparticles Depend on the Shape of the Nanoparticle? A Study of the Gram-Negative Bacterium Escherichia coli. Appl. Environ. Micorbiol. 73: 1712-1714. DOI: 10.1128/AEM.02218-06

Prabhu S and Poulose EK (2012) Silver nanoparticles: mechanism of antimicrobial action, synthesis, medical applications, and toxicity effects. Intl. Nano Lett. 2: 32. DOI: 10.1186/22285326-2-32

Rai M, Yadav A and Gade A (2009) Silver nanoparticles as a new generation of antimicrobials. Biotechnol. Adv. 27: 7683.DOI: $10.1016 /$ j.biotechadv.2008.09.002

Sondi I and Salopek-Sondi B (2004) Silver nanoparticles as antimicrobial agent: a case study on E. coli as a model for Gram-negative bacteria. J. Colloid Interface. Sci. 275: 177182. DOI: 10.1016/j.jcis.2004.02.012

Varshney R, Bhadauria S and Gaur MS (2010) Biogenic synthesis of silver nanocubes and nanorods using sundried Stevia rebaudiana leaves Biogenic synthesis of silver nanocubes and nanorods using sundried Stevia rebaudiana leaves. $A d v$. Mat. Lett. 1(3): 232-237. DOI: 10.5185/amlett.2010.9155 